\title{
GIS Based Surveillance of Road Traffic Accidents (RTA) Risk for Rawalpindi City: A Geostatistical Approach
}

\author{
Amna Butt, Sheikh Saeed Ahmad*, Rabia Shabbir and Summra Erum \\ Fatima Jinnah Women University, the Mall, Rawalpindi, Pakistan
}

\begin{abstract}
Identification of previously existing traffic accident hotspots is the first step to ensure future road safety. The present study focused on providing GIS based geostatistical surveillance for the Road Traffic Accidents (RTA) in Rawalpindi for five years (2009-2013) to determine the high risk areas or hotspots. For this purpose, spatial autocorrelation (Moran's I test), Standard Deviational Ellipse (SDE) and hotspot (Getis-Ord Gi*) analyses were performed on the data obtained from Punjab Emergency Service Department (Rescue 1122). Spatial clusters and hotspots identified during the research lied mostly in the Northern and Northeastern part of the study area encompassing both commercial and residential areas of the city with majority of accident hotspots being near schools, hospitals, airport and highways. The study proposed that serious steps should be taken to improve the road safety conditions in these areas and focus of Emergency Response Providers (ERPs) should be directed there. Furthermore, the integration of GIS based expertise in the Emergency department should be ensured for regular surveillance of shifts in hotspots.
\end{abstract}

Keywords: Road Traffic Accidents (RTA), GIS, Geostatistical analysis, Hotspots (Getis-Ord Gi*), Spatial Autocorrelation, Moran's I test, Standard Deviational Ellipse (SDE)

\section{Introduction}

RTAs are most common emergencies of present day and age. With passage of time, the incidence of RTA has significantly increased in Pakistan (Butt, 2013; Hyder, Ghaffar, Sugerman, Masood \& Ali, 2006). This alarming rate is due to lack of public awareness and observation of traffic rules and regulations. According to Pakistan Bureau of Statistics (PBS), approximately 9000 road accidents were reported to police every year since 2011 . On average these accidents were responsible for killing over 4500 people (Sikander, Haider \& Rafi, 2015).

Mounting frequency of these RTAs makes it necessary for a quick and efficient emergency response system, especially the ambulance facility, to be there for catering these accidents (Abbasi, Pirzada \& Hanif, 2013). Therefore, for the provision of apt and timely response for these traffic accidents faced by Pakistan, there is a need of strong inter and intra-national collaboration and fund allocation as well as well-organized and highly trained EFR providers.
Several major factors involving timely acquisition of requisite information, lack of resources and infrastructure and contingency planning hinder the timely and efficient EFR provision. Numerous initiatives have been taken worldwide to develop such incident response measures that will deal with each incident in timely and effective manner. This requires, among other things, deployment of appropriate response units to the incident locations.

GIS tools provide a proactive approach for early identification of the emergency hotspots and lead to less resource utilization. Studies disclose that GIS tool is very effective for both First Responders and Emergency Management especially in terms of resource management. The specific applications of GIS having potential to play a key role in emergency response improvement comprise spatial autocorrelation (Prasannakumar, Vijith, Charutha \& Geetha, 2011), hotspot detection (Thariqa \& Sitanggang, 2015; Amri \& Sitanggang, 2015), spatial centrographic analysis (Lee, 2009) and density analysis (Erdogan, Yilmaz, Baybura \& Gullu, 2008).

* Corresponding author

E-mail: drsaeed@fjwu.edu.pk

(C) 2015 International Association for Sharing Knowledge and Sustainability

DOI: $10.5383 /$ swes.7.02.002 
The significance of integrating GIS in emergency management is thus evident through the amount of literature published every year exemplifying its applications in supplementing the aforementioned necessities for ERI.

\section{Materials and Methods}

\section{Study Area}

Rawalpindi city, commonly known as Pindi (Figure 1), was the study area of the current research work. It lies between $33^{\circ}$ $28^{\prime}$ and $33^{\circ}-48^{\prime}$ North latitudes and $72^{\circ}-48^{\prime}$ and $73^{\circ}-22^{\prime}$ East longitudes and is administratively divided in to two tehsils: Rawal and Potohar. Rawalpindi is one of the historic cities in Potohar Plateau and covers 250 square kilometer area with population of about 2.2 million.

Currently Rescue 1122, alternatively known as Punjab Emergency service, is providing rescue and first aid services to the victims of RTA in the city. The organization has 5 service stations and 2 keypoints located in different parts of the city and has meager resources available for emergency first response provision including 14 ambulances, 2 special vehicles, 2 recovery vehicles, 2 rescue vehicles, 9 fire vehicles and 1 water rescue van (Abbasi et al., 2013).

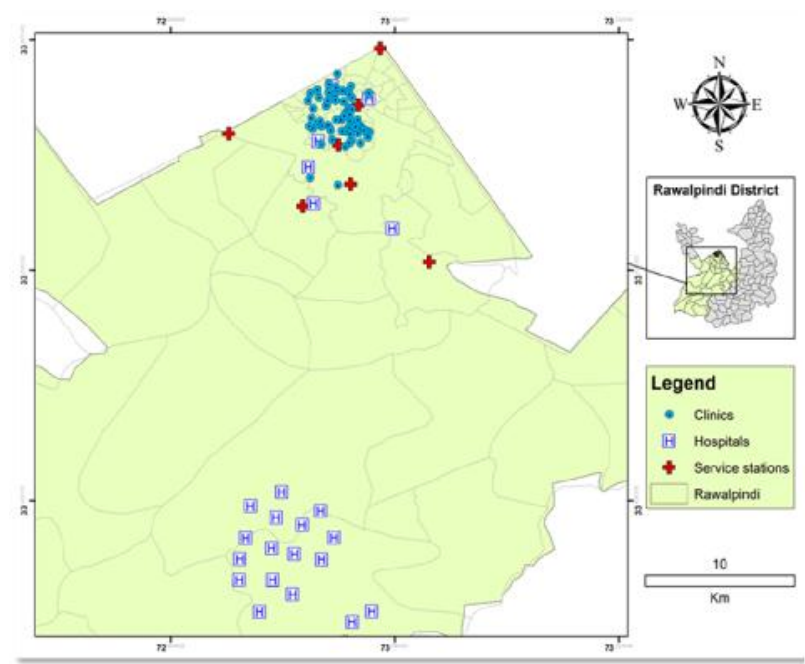

Figure 1: Study Area Map Showing Service Stations of 1122

\section{Data Collection and Processing}

As shown in Figure 2, the first step of research methodology was unit level data collection from the headquarters of Rescue 1122, Rawalpindi. This data, containing the emergency data in form of call record (caller and victim directory), was obtained from all the rescue stations at work in the city. The data was processed in Microsoft Excel 10 to prepare extract data on RTA victims on basis of which GPS locations of victims' addresses was acquired. The final sheets were then added to ArcGIS for further analysis.

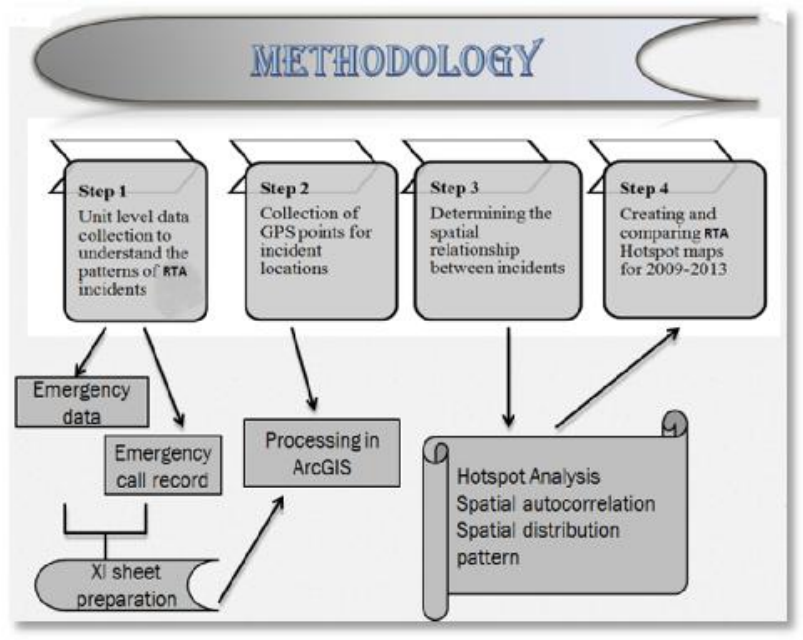

Figure 2: Research Methodology Flowchart

\section{Geostatistical Analysis of Emergency Data}

The Geostatistical Analyses that were performed on the data comprised Spatial Autocorrelation Analysis (Moran's I test), Hotspot Analysis (Getis-Ord Gi*) and Centrographic Statistics (Standard deviational ellipse and mean center).

\section{- Centrographic Analysis (Standard deviational ellipse)}

Mapping incidents is the first step in any spatial analysis, which is why standard deviational ellipse and mean center analysis were performed on the data to determine and map the directional distribution trend of RTA cases for study duration. SDE parameter was calculated for RTAs for each year from 2009-2013 and overlaid to compare the extent of RTA incidents and their global position. SDE parameter takes in to account spreading of features in one direction than in another farther from a specified point (Ebdon, 1991).

\section{- Spatial Autocorrelation Analysis (Moran's I test)}

Spatial autocorrelation analysis or Global Moran's I statistic determines the characteristics of the global pattern by estimating existing correlation among spatial observations (in this case RTA incidents). The pattern could either be random, dispersed and clustered based on the association among features (Boots \& Getis, 1998; Fang et al., 2006). The statistical significance of the observed clustering or dispersing in the features is assessed by ' $Z$ ' score value. Positive value of score indicates towards significant clustering while negative gives an indication of dispersion.

\section{- Hotspot Analysis (Getis-Ord Gi*)}

Getis-Ord Gi* statistics generally identifies the locations over the whole study area as hotspots, cold spots or mild spot locations with statistical significance. Where, hotspots are the areas more prone to a particular incident or are the high risk areas for an incident to occur. Z-score statistics is calculated for every feature in a dataset and statistically significant positive Z-score (having larger value) represents intense clustering (hotspots). Nevertheless, the detection of hotspot can still be valuable even if data does not reveal clustering (Getis \& Ord, 1992; Wu et al., 2004; Feser, Sweeney \& Renski, 2005): 


\section{Results}

For determination of contemporary status of RTA occurrences via GIS, the emergency callout data for 2009 to 2013 was collected and processed. Various analyses were performed on the data to determine the pattern of emergencies. The total cases of RTA reported for the duration of 2009-2013 were 22828 of which $88 \%$ (20053) were reportedly males whereas $12 \%$ (2759) were females. In 2009, 2559 cases were accounted and this number augmented to 4255 in 2010 and followed the increasing trend in subsequent years too, with 4770 reported in 2011 and 5016 and 6228 for 2012 and 2013 respectively.

The result of centrographic statistical analysis for RTA incidents for each year (Figure 3) revealed that both urban and rural areas of Rawalpindi city were observed within SDE for each year. Global distributional patterns showed slight differences for the study period with gradual decrease in the ellipse area until 2011, which subsequently increased in 2012 and again decreased in 2013. This revealed that the RTA cases were widely distributed in 2009 as compared to all the subsequent years and showed an overall random distribution pattern.

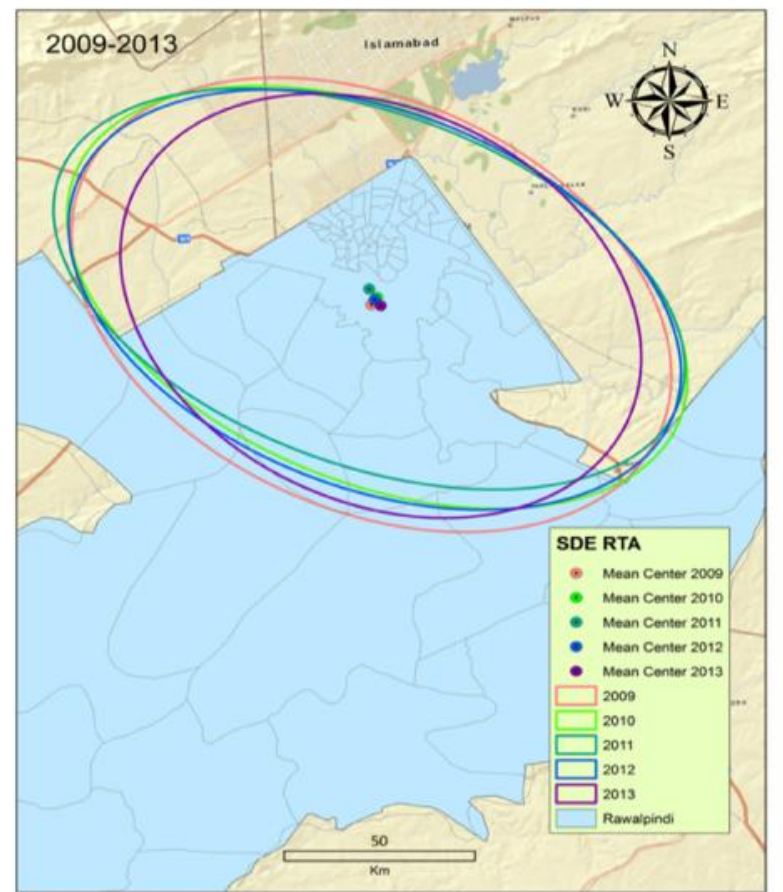

Figure 3: SDE Map Showing Distributional Pattern of RTAs for Study Duration
Moran's statistic (I) weighted for 2009, 2010, 2011, 2012 and 2013 was 0.026 ( $Z$-score $=1.44, \mathrm{P}=0.1), 0.008$ ( $\mathrm{Z}$-score $=0.65$, $\mathrm{P}=0.6), 0.0005(\mathrm{Z}$-score $=2.44, \mathrm{P}=0.01),-0.003(\mathrm{Z}$-score $0.84, \mathrm{P}=0.3$ ) and -0.003 (Z-score $=0.38, \mathrm{P}=0.7$ ) respectively. Thus based on Moran's autocorrelation statistic, RTA cases for all the years but 2011 had random spatial distribution pattern (Table 1).

Table 1: Spatial Autocorrelation Statistics of RTA Incidents

\begin{tabular}{c|llll|}
\hline \multicolumn{1}{c|}{ Year } & Moran's I & Z Score & P Value & Pattern \\
\hline \hline $\mathbf{2 0 0 9}$ & 0.0260 & 1.44003 & 0.14986 & Random \\
$\mathbf{2 0 1 0}$ & 0.0084 & 0.65778 & 0.51068 & Random \\
$\mathbf{2 0 1 1}$ & 0.00053 & 2.44907 & 0.01432 & Clustered \\
$\mathbf{2 0 1 2}$ & -0.0034 & 0.8433 & 0.39906 & Random \\
$\mathbf{2 0 1 3}$ & -0.0038 & 0.38127 & 0.70301 & Random
\end{tabular}

The RTA hotspots for each year from 2009-2913 (Figure 4) were estimated by employing Getis-Ord Gi* statistic. Hotspots for RTA cases were mostly seen in Northern, North Western and North Eastern parts of the study area. . The specific hotspot locations for each year are tabulated in Table 2 however.

Table 2: Identified RTA Hotspots for the Years 2009-2013

\begin{tabular}{cl}
\hline Year & Identified Hotspot Locations \\
\hline 2009 & Rawal road, Westridge, Misriyal road, Choor chowk, \\
& British Homes, Sohan Pull, Faizabad, Faiz-ul-Islam, \\
& Seham road, Allahabad, Peshawar road, Peerwadhai \\
& Morr, PAF Chowk and Fouji Tower Chowk \\
& Rawal road, Rawat Chowk, Holy Family Hospital \\
& road, Westridge, Misriyal road, Choor chowk, British \\
& Homes, Faiz-ul-Islam, Seham road, Allahabad, \\
& Peshawar road, Peerwadhai Morr, PAF Chowk, Fouji \\
& Tower Chowk, Faizabad, Mandi Morr, Sohan Pull, \\
& and Mehrabad Chowk \\
& IJP road, Fauji Colony, Carriage Factory, Sohan Pull, \\
& Margallah Town, Westridge, Misriyal road, Mandi \\
& Morr, Peerwadhai Morr, Seham road, Rawal road, PAF \\
& Chowk, Choor Chowk and Allahabad \\
Murree road, Faizabad, Sixth road, Islamabad \\
Highway, Adyala road, Airport road, Askari 8, Bhabra \\
Bazar, Karaal Chowk, Ayub Park, Police Line, Jinnah \\
Park, Kachehri Chowk, Choor Chowk, Waris Khan \\
Stop and Peshawar road \\
Mall road, Rawat Chowk, Gawalmandi, Committee \\
Chowk, Murree road, Liaqat Bagh Chowk, Sixth road, \\
Double road, Highway road, Adyala road, Kachehri \\
Chowk, Chandni Chowk, Airport, Karaal Chowk, \\
Sohan Pull and DHA
\end{tabular}


Figure 4 revealed that RTA hotspots for 2009 and 2010 were located mainly in the same regions but their extent increased slightly in the later year. For 2011, the hotspots became more contained towards North Western portion of the study area. The hotspot locations for 2012 and 2013 shifted slightly toward South-East direction however.
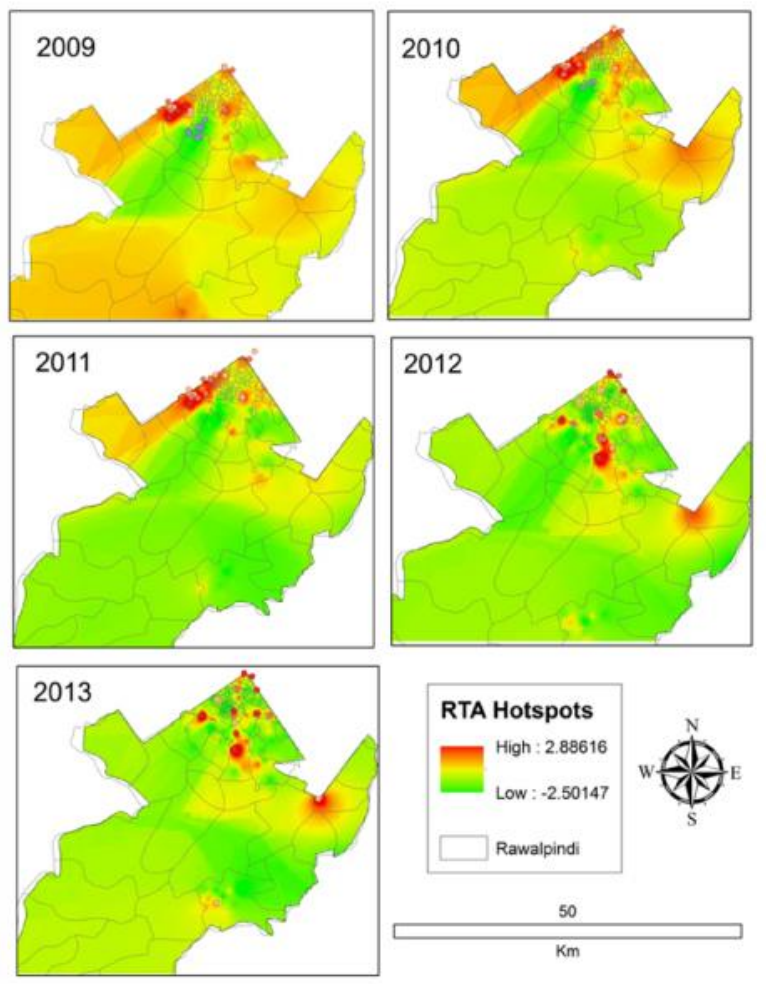

Figure 4: Mapping of RTA Hotspots and Cold Spots Using GetisOrd G* Statistics During 2009-2013

Cold spot clusters for RTA incidents conversely were contained mainly in Northern regions of the study area including were Tench Bhata, People Colony, R.A. Bazar and Kalma Chowk.

\section{Discussion}

The results obtained signified towards a considerable augmentation in the intensity of RTA cases for the duration of the study. Rescue 1122 dealt with majority of the RTA cases in the city and has reportedly provided response to such emergencies for the past decade (Saleem, 2014; The Express Tribune, 2014, 2013).

Mean centers for RTA cases displayed similar displacement tendency throughout the study duration with slight differences in angle of rotation. The size of ellipses ring contrariwise varied from year to year and was largest in 2011.

The spatial autocorrelation analysis (Moran's I test) for the current study suggested that RTA incidents only showed significant clustering in 2011. Other researches also obtained results with no significant clustering in the data but the results were still effective for hotspot detections (Fan \& Myint, 2014; Hussain et al., 2013). Significant RTA hotspots were pronounced in the areas with poor lighting and high-speed highways, dangerous $U$ turns, complex intersections and extremely busy and congested roads. Most vulnerable roads of Rawalpindi with respect to RTA included Peshawar road, Rawal road, IJP road and Islamabad Highway. Daily Times (2015) reported that DEO Rawalpindi also categorized these roads as most susceptible to accidents.

Additionally, significantly augmented risk areas of RTA injuries included roads near schools, local airport, gas stations, bus stops, pedestrian crossings and other suburban highactivity passageways. Similar results were obtained by Nasir et al. (2015), Ponnaluri (2012a, b), Clifton, Burnier \& Akar (2009) and Coate \& Markowitz (2004) while analyzing the hotspots for RTAs.

\section{Conclusion and Recommendations}

This research presented an incorporation of different GIS based techniques for in-depth spatio-temporal analysis and geostatistical surveillance of emergency response situations prevailing in Rawalpindi city. The main focus of the research was on RTA emergencies; however. The results indicated towards both spatial and temporal variations in the incidence of the RTA emergencies. Most of emergency hotspots were observed in Rawal tehsil with very few hotspots in Potohar region. The clustering of emergencies was also variable with significant clustering observed only for 2011. Furthermore, the incidents of emergencies augmented over time even as the hotspots became randomly distributed. Based on the research outcomes, it is recommended that the focus of Rescue 1122 be sifted to upper region of Rawalpindi city where the majority of hotspots lie. The study further recommends incorporation of GIS based expertise in the emergency department to provide real time analysis for further improvement of emergency first response in the city as well as ensure proper resource allocation. The study could thus be used as a benchmark by EFR providers in the city and serve as a reference at both national and international level with similar conditions.

\section{References}

[1] Abbasi, M.A., Pirzada, M.D., \& Hanif, A. (2013). On the Rescue- 1122: Quality Enhancement in Emergency First Response. Information Technology \& Electrical Engineering (ITEE) Journal, 2(4), 44-47.

[2] Amri, K., \& Sitanggang, I.S. (2015). A Geographic Information System for hotspot occurrences classification in Riau Province Indonesia. Procedia Environmental Sciences, 24, 127-131.

[3] Boots, B.N., \& Getis, A. (1998). Point Pattern Analysis Newbury Park. Newbury Park, CA, USA: Sage Publications.

[4] Butt, M. A. (2013). Improving safety and quality in Emergency First Response in Rawalpindi district, Punajb, Pakistan. Middle East Journal of Business, 8(2), 31-35.

[5] Clifton, K.J., Burnier, C.V., \& Akar, G. (2009). Severity of injury resulting from pedestrian-vehicle crashes: what can we learn from examining the built environment. Transportation Research, 14, 425-436. 
[6] Coate, D., \& Markowitz, S. (2004). The effects of daylight and daylight saving time on US pedestrian fatalities and motor vehicle occupant fatalities. Accident Analysis and Prevention, 36, 351-357.

[7] Daily Times. (2015, May, 31). Emergency management plan discussed: Five roads prone to traffic accidents, says Rescue 1122. Daily Times. Retrieved from http://archives.dailytimes.com.pk/islamabad/06-Jan2010/emergency-management-plan-discussed-five-roadsprone-to-traffic-accidents-says-rescue- 1122

[8] Ebdon, D. (1991). Statistic in geography: A practical approach (2nd edition). Malden, MA, USA: Blackwell Publishing.

[9] Erdogan, S., Yilmaz, I., Baybura, T., \& Gullu, M. (2008). Geographical information systems aided traffic accident system case study: city of Afyonkarahisar. Accident Analysis and Prevention, 40, 174-181.

[10] Fan, C., \& Myint, S. (2014). A comparison of spatial autocorrelation indices and landscape metrics in measuring urban landscape fragmentation. Landscape and Urban Planning, 121, 117-128.

[11] Fang, L., Yan, L., Liang, S., Vlas, S.J.D., Feng, D., Han, X., Zhao, W., Xu, B., Bian, L., Yang, H., Gong, P., Richardus, J.H., \& Cao, W. (2006). Spatial analysis of hemorrhagic fever with renal syndrome in China. BMC Infectious Diseases, 6, 77-88.

[12] Feser, E., Sweeney, S., \& Renski, H. (2005). A descriptive analysis of discrete U.S. industrial complexes. Journal of Regional Science, 45, 395-419.

[13] Getis, A., \& Ord, J.K. (1992). The analysis of spatial association by use of distance statistics. Geographical Analysis, 24(3), 189-206.

[14] Hussain, M.H., Ward, M.P., Body, M., Al-Rawahi, A., Wadir, A.A., Al-Habsi, S., Saqib, M., Ahmed, M.S., \& Almaawali, M.G. (2013). Spatio-temporal pattern of sylvatic rabies in the Sultanate of Oman, 2006-2010. Preventive Veterinary Medicine, 110, 281-289.

[15] Hyder, A.A., Ghaffar, A.A., Sugerman, D.E., Masood, T.I. \& Ali, L. (2006). Health and road transport in Pakistan. Public Health, 120, 132-141.

[16] Lee, J. (2009). Statistics, Descriptive. International Encyclopedia of Human Geography, 2, 422-428.
[17] Nasir, A., Chaudhry, A.G., Ahmad, A., \& Shamim, F. (2015). Urban traffic jams, health emergencies and architectural perspective. Science International, 27(1), 611-613.

[18] Ponnaluri, R.V. (2012a). Road traffic crashes and risk groups in India: Analysis, interpretations, and prevention strategies. IATSS Research, 35, 104-110.

[19] Ponnaluri, R.V. (2012b). Modeling road traffic fatalities in India: Smeed's law, time invariance and regional specificity. IATSS Research, 36, 75-82.

[20] Prasannakumar, V., Vijith, H., Charutha, R., \& Geetha, N. (2011). Spatio-Temporal Clustering of Road Accidents: GIS Based Analysis and Assessment. Procedia Social and Behavioral Sciences, 21, 317-325.

[21] Saleem, M. (2014). Outstanding performance showed in 2014 Rescue-1122 to mark 2015 as 'Year of Safety'. Retrieved from http://epaper.brecorder.com/m/2015/01/02/19page/477300-news.html

[22] Sikander, T., Haider,S., \& Rafi, Y. (2015, April, 10). Pakistan's traffic accidents record: Punjab down, KP up since 2011. The DAWN. Retrieved from: http://www.dawn.com/news/1143784.

[23] Thariqa, P., \& Sitanggang, I.S. (2015). Spatial online analytical processing for hotspots distribution based on socio-economic factors in Riau Province Indonesia. Procedia Environmental Sciences, 24, 277-284.

[24] The Express Tribune. (2014, August, 2). Timely response: Rescue 1122 chief lauds services during Eid. The Express Tribune. Retrieved from http://tribune.com.pk/story/743086/timely-responserescue-1122-chief-lauds-services-during-eid/

[25] The Express Tribune. (2013, October, 4). Emergency operations: Rescue 1122 saved 1,492 lives in September. The Express Tribune. Retrieved from http://tribune.com.pk/story/613199/emergency-operationsrescue-1122-saved-1492-lives-in-september/

[26] Wu, J., Wang, J., Meng, B., Chen, G., Pang, L., Song, X., Zhang, K., Zhang, T., \& Zheng, X. (2004). Exploratory spatial data analysis for the identification of risk factors to birth defects. BMC Public Health, 4, 23-32. 